\title{
Lieutenant Suffers Sudden Cardiac Death During the "Pack Test" - Arizona
}

\section{Executive Summary}

On March 8, 2014, a 61-year-old male paid-call lieutenant (LT) performed the

U. S. Forest Service arduous duty Work Capacity Test (WCT), also known as the "Pack Test." The test is a required component of "red card certification" allowing wildland firefighters to work on federal property. The Pack Test requires a 3-mile walk within 45 minutes while wearing a 45-pound weighted vest. After completing 6 laps around the track (1.5 miles), the LT stumbled, appeared dizzy, and then collapsed. Crewmembers assessed him and found him unresponsive, not breathing, and without a pulse; they initiated cardiopulmonary resuscitation (CPR) and advanced life support (ALS). Despite CPR and ALS on-scene and in the hospital's emergency department (ED), the LT could not be revived. The death certificate and the autopsy, completed by the County Medical Examiner, listed "complications of acute myocardial infarct (heart attack)" due to "hypertensive and arteriosclerotic cardiovascular disease" as the cause of death. The LT had a left ventricular rupture and cardiac tamponade. Prior to this incident, the LT was not known to have coronary heart disease (CHD). The NIOSH investigators concluded that the physical stress of the Pack Test probably precipitated his left ventricle rupture in an area weakened by an asymptomatic heart attack occurring approximately 1 week earlier.
It is unclear if any of the following recommendations would have prevented the LT's death. Nonetheless, NIOSH investigators offer the following recommendations to reduce the risk of heart attacks and sudden cardiac arrest among fire fighters at this and other FDs.

Provide preplacement and annual medical evaluations to all fire fighters consistent with NFPA 1582, Standard on Comprehensive Occupational Medical Program for Fire Departments, to identify fire fighters at increased risk for CHD.

Perform exercise stress tests on fire fighters at increased risk for CHD.

Check Pack Test participants'vital signs before testing.

Require the completion of a Health Screen Questionnaire (HSQ) prior to participating in the Pack Test. 


\section{Lieutenant Suffers Sudden Cardiac Death During the “Pack Test"}

- Arizona

The National Institute for Occupational Safety and Health (NIOSH), an institute within the Centers for Disease Control and Prevention (CDC), is the federal agency responsible for conducting research and making recommendations for the prevention of work-related injury and illness. In 1998, Congress appropriated funds to NIOSH to conduct a fire fighter initiative that resulted in the NIOSH "Fire Fighter Fatality Investigation and Prevention Program" which examines line-of-duty-deaths or on duty deaths of fire fighters to assist fire departments, fire fighters, the fire service and others to prevent similar fire fighter deaths in the future. The agency does not enforce compliance with State or Federal occupational safety and health standards and does not determine fault or assign blame. Participation of fire departments and individuals in NIOSH investigations is voluntary. Under its program, NIOSH investigators interview persons with knowledge of the incident who agree to be interviewed and review available records to develop a description of the conditions and circumstances leading to the death(s). Interviewees are not asked to sign sworn statements and interviews are not recorded. The agency's reports do not name the victim, the fire department or those interviewed. The NIOSH report's summary of the conditions and circumstances surrounding the fatality is intended to provide context to the agency's recommendations and is not intended to be definitive for purposes of determining any claim or benefit. For further information, visit the program website at www.cdc.gov/niosh/fire or call toll free 1-800-CDC-INFO (1-800-232-4636). 


\section{Lieutenant Suffers Sudden Cardiac Death During the "Pack Test" - Arizona}

\section{Introduction \& Methods}

On March 8, 2014, a 61-year-old male LT suffered sudden cardiac death during his Pack Test. Despite CPR and ALS performed by crewmembers, ambulance service personnel, and physicians in the hospital's ED, the LT died. The United States Fire Administration notified NIOSH of this fatality on March 10, 2014. NIOSH contacted the affected FD on March 14, 2014, to obtain further information and on June 5, 2014, to initiate the investigation. On June 24, 2014, a Safety and Occupational Health Specialist from the NIOSH Fire Fighter Fatality Investigation Team traveled to Arizona to conduct an on-site investigation of the incident.

During the investigation NIOSH personnel met and/or interviewed the following people:

- Acting Fire Chief

- LT's crewmembers

- Pack Test Administrator, who also was the FD Training Officer

- LT's wife

During the site visit NIOSH personnel reviewed the following records:

- FD training records

- FD annual response report for 2013

- Primary care physician records

- Ambulance report

- Death certificate

- Autopsy report

\section{Results of Investigation}

On March 8, 2014, at 0730 hours, the LT arrived at his fire station to participate in the FD-scheduled U.S. Forest Service arduous duty WCT, also known as the "Pack Test." Seven other fire fighters were scheduled to take the test. After arriving at the fire station and retrieving the equipment and water, the crew departed for the local high school track. The FD's on-duty crew remained at the track to assist.

All attendees were briefed, drank water, donned the weighted vests, and stretched. The Training Officer began the test at approximately 0800 hours. The LT completed 6 laps without difficulty (1.5 miles in 23 minutes) but as he began lap 7, he stumbled, appeared dizzy, and then collapsed. A crewmember caught the LT and assisted him to the ground; he was unresponsive with agonal breathing. Crewmembers initially thought he was suffering from heat exhaustion, possibly heat syncope. After removing his vest and elevating his feet, further assessment revealed the LT had no pulse. As medical equipment was retrieved, an ambulance and a neighboring city engine company were requested (0831 hours).

Crewmembers began CPR and ALS including cardiac monitoring which revealed pulseless electrical activity and asystole. An intravenous line was inserted, cardiac resuscitation medications were administered, and an oral airway for oxygen was placed. Engine paramedics arrived on-scene at 0835 hours. After a second round of cardiac medications was administered, the LT's heart rhythm went into ventricular fibrillation and a shock was delivered; his heart rhythm reverted to pulseless electrical activity. CPR continued as the LT was intubated, with tube placement confirmed by breath sounds and capnography [Neumar et al. 


\section{Lieutenant Suffers Sudden Cardiac Death During the "Pack Test" - Arizona}

\section{Results of Investigation (cont.)}

2010]. The ambulance departed the scene at 0845 hours en route to the ED, arriving at 0852 hours.

Inside the ED, ALS measures continued without a change in the LT's clinical status. Cardiac resuscitation efforts continued until 0917 hours, when the attending physician pronounced the LT dead and resuscitation efforts were discontinued. Subsequent blood testing revealed a markedly elevated level of troponin I (5.57 nanograms per milliliter $[\mathrm{ng} / \mathrm{mL}][$ normal $<0.05])$. Troponin I is a protein released into the blood when the heart muscle is damaged [NIH 2014]. Troponin I levels become elevated about 6 hours after a heart attack and these levels persist for 1 to 2 weeks [NIH 2014].This finding suggests the LT suffered a heart attack days or weeks prior [Ellis 1991; Mair et al. 1992; Antman et al. 1995]. The autopsy findings, described below, confirm this timing of events.

Medical Findings. The death certificate and the autopsy, completed by the County Medical Examiner, listed "complications of acute myocardial infarct" over days due to "hypertensive and arteriosclerotic cardiovascular disease" occurring over years as the cause of death. The complications included a transmural tear in an area of damaged (necrotic) tissue in the LT's left ventricle. This tear resulted in acute bleeding into the pericardial sac (hemopericardium) and constricted the heart's ability to function (cardiac tamponade). The necrotic tissue was due to a heart attack that occurred days to weeks earlier; evidence for the heart attack included the LT's troponin I levels and an organizing blood clot (thrombus) in the LT's left anterior descending coronary artery. See Appendix A for additional findings from the autopsy.
At his last medical evaluation (September 2013) by his primary care physician, the LT weighed 183 pounds giving him a body mass index of 24 kilograms per square meter (normal) [CDC 2014]. The LT had a history of hyperlipidemia. His most recent tests (September 2013) showed a triglyceride level of 195 milligrams per deciliter (mg/dL) (normal), a cholesterol level of $217 \mathrm{mg} /$ $\mathrm{dL}$ (normal is $100-199 \mathrm{mg} / \mathrm{dL}$ ), a high density lipoprotein level of $46 \mathrm{mg} / \mathrm{dL}$ (normal), and a low density lipoprotein level of $32 \mathrm{mg} / \mathrm{dL}$ (normal). He was not prescribed cholesterol-lowering medication or diet modification. He was not known to be hypertensive; he had normal annual blood pressure readings over 13 years except for one elevated diastolic reading of 92 millimeters of mercury (mmHg) in September 2013.

About 1 month prior to this incident, the LT complained of rib pain attributed to a pulled muscle when he was repairing an FD engine. After taking over-the-counter pain medication, the pain subsided. On March 2, 2014, the LT complained of "not feeling well." No additional symptoms or complaints were mentioned. An informal electrocardiogram (EKG) performed by paramedics at his fire station revealed a slight ST-segment depression, which was considered insignificant; immediate evaluation by a physician was not considered necessary. The LT was advised to follow-up with a physician, and had scheduled an appointment with a cardiologist for March 10, 2014 (2 days after this incident). The record of the informal EKG taken 6 days earlier was discarded and not available for review. It is unclear if the LT's earlier heart attack occurred on the job and if it was triggered by work activities. 


\section{Lieutenant Suffers Sudden Cardiac Death During the "Pack Test" - Arizona}

\section{Description of the Fire Department}

At the time of the NIOSH investigation, the FD consisted of three fire stations with 42 (11 fulltime and 31 volunteer) uniformed personnel. The FD served 4,600 residents in a geographic area of 34 square miles. In 2013, the FD responded to 336 fire/rescue calls.

Membership and Training. The FD requires fire fighter applicants to be 18 years of age, have a valid state driver's license, perform three ridealongs, and pass the following before being offered membership/employment: officer evaluation, three-panel interview, background check, preplacement medical evaluation (discussed below), physical agility test (Appendix B), and Fire Chief's interview. The new member is on probation for 1 year and has 2 years to complete Fire Fighter I and II and Emergency Medical Technician certifications. The LT was trained as a Fire Fighter I and II, Apparatus Operator, Emergency Medical Technician, Fire Officer, Wildland Fire Fighter, and in Hazardous Materials Awareness. He had 15 years of fire fighting experience.

Medical Evaluations. Preplacement medical evaluations are required by the FD. The medical evaluations are performed by an FD-contracted physician who makes a determination regarding medical clearance for fire fighting duties and forwards this decision to the FD. Components of this evaluation include the following:

- Complete medical history

- Physical examination (including vital signs - height, weight, blood pressure, pulse, and respirations)

- Vision test (acuity, color, peripheral fields, and depth perception)

- Audiogram
- Urinalysis

- Urine drug screen

- Self-contained breathing apparatus respirator clearance

Annual medical evaluations are not required. When members are injured on duty, a drug test and medical clearance for return to duty by the treating physician are required. If a member is ill and misses more than two shifts, a medical clearance is required by their primary care physician, who forwards a determination for return to duty to the FD. Annual facepiece fit testing is conducted as required by OSHA [OSHA 2011] under the approved plan for Arizona.

Health and Wellness Programs. The FD has a mandatory wellness/fitness program and exercise equipment is available in all fire stations. An annual job performance physical ability test is required for all members (Appendix B) as required by NFPA 1500, Standard on Fire Department Occupational Safety and Health Program [NFPA 2013a]. The LT regularly participated in physical fitness activities.

Pre-placement/Pre-WCT Evaluations. Before training for the WCT or the duties of the job, the Administrator's Guide states that the candidate must complete an HSQ (or medical history) designated by the hiring agency [Whitlock and Sharkey 2003]. Depending on the results of the HSQ and the age of the candidate, the agency may require a medical examination. Once individuals have received medical clearance, they may begin training for the WCT. In Arizona, the State did not require that WCT candidates be medically cleared, pass a medical examination, or complete an HSQ prior to the Walk Test, the more arduous Field Test, or the most arduous Pack Test [Sharkey and Gaskill 2009]. 


\section{Lieutenant Suffers Sudden Cardiac Death During the "Pack Test" - Arizona}

\section{Discussion}

Cardiac Tamponade. In cardiac tamponade, blood or fluid collects in the sac around the heart. This accumulation constricts the heart, which prevents it from filling properly, and causes a sharp drop in blood pressure. Unless treated immediately, fatal cardiac tamponade typically ensues [Braunwald 2008; AHA 2013].

Left Ventricular Rupture. In patients with acute myocardial infarction, left ventricular free wall rupture is an infrequent complication (2-4\%) but it is associated with a high mortality from pericardial tamponade [Figueras et al. 2000; Amir et al. 2005]. Risk factors, or triggering factors, for free wall rupture include age $>55$ years, the presence of persistent arterial hypertension $(\geq 150$ $\mathrm{mmHg}$ ) during the first 10-24 hours of the acute infarction, and significant physical effort [Figueras et al. 2000; Amir et al. 2005]. Late rupture ( $\geq 24$ hours between onset of symptoms and hospital admission) is associated with physical exercise probably due to rupture of the necrotic tissue caused by the heart attack [Figueras et al. 1998; Figueras et al. 2000; Raposo et al. 2006]. The LT probably suffered a heart attack approximately 1 week prior to this incident as evidenced by an organizing thrombus in his left anterior descending coronary artery and focal area of necrotic tissue in the left ventricle. The physical exertion associated with the Pack Test probably triggered a rupture of the LT's left ventricle.

\section{Atherosclerotic Coronary Heart Disease} and Heart Attacks. In the United States, atherosclerotic CHD is the most common risk factor for cardiac arrest and sudden cardiac death [Meyerburg and Castellanos 2008]. Risk factors for its development include age older than 45, male gender, family history of coronary artery disease (CAD), smoking, high blood pressure, high blood cholesterol, obesity/physical inactivity, and diabetes [NHLBI 2012; AHA 2014]. The LT had one known modifiable CHD risk factor (high blood cholesterol), although his autopsy showed signs of longstanding hypertension (left ventricular hypertrophy, borderline cardiomegaly, and nephrosclerosis).

The narrowing of the coronary arteries by atherosclerotic plaques occurs over many years, typically decades [Libby 2013]. However, the growth of these plaques probably occurs in a nonlinear, often abrupt fashion. Heart attacks typically occur with the sudden development of complete blockage (occlusion) in one or more coronary arteries that have not developed a collateral blood supply. This sudden blockage is primarily due to blood clots (thrombosis) forming on ruptured atherosclerotic plaques [Libby 2013]. Establishing a recent heart attack requires any of the following: elevated cardiac enzymes, coronary artery thrombus, or characteristic EKG changes. In this case, the LT had elevated cardiac enzymes (troponin I), an organizing thrombus revealed at autopsy, as well as a focal necrotic area of myocardium in the distribution of the left anterior descending coronary artery. The EKG taken 6 days prior was reported to have abnormalities, but none of the characteristic changes of an acute heart attack. Finally, chest pain (angina) typically accompanies a heart attack. The LT reported rib pain 1 month prior to this incident and then "not feeling well" 6 days prior. It is unclear if these symptoms represented angina or whether the LT experienced a "silent" heart attack [Thaulow et al. 1993; Libby 2008]. 


\section{Lieutenant Suffers Sudden Cardiac Death During the "Pack Test" - Arizona}

\section{Discussion (cont.)}

Occupational Medical Standards for Structural Fire Fighters. To reduce the risk of sudden cardiac arrest or other incapacitating medical conditions among fire fighters, the National Fire Protection Association (NFPA) developed NFPA 1582, Standard on Comprehensive Occupational Medical Program for Fire Departments [NFPA 2013b]. This voluntary industry standard provides the components of a preplacement and annual medical evaluation and medical fitness for duty criteria. The LT's underlying CHD was not identified until after this incident. Recommendations on whether to screen asymptomatic individuals for CHD using EST are varied. The following paragraphs summarize the positions of widely recognized organizations on this topic.

NFPA 1582, a voluntary industry standard, recommends an EST performed "as clinically indicated by history or symptoms" and refers the reader to Appendix A [NFPA 2013b]. Items in Appendix A are not standard requirements, but are provided for "informational purposes only." Appendix A recommends using submaximal (85\% of predicted heart rate) EST as a screening tool to evaluate a fire fighter's aerobic capacity. Maximal (i.e., symptom-limiting) EST with imaging should be used for fire fighters with the following conditions:

- abnormal screening submaximal tests

- cardiac symptoms

- known CAD

- one or more risk factors for CAD (in men older than 45 and women older than 55)

Risk factors are defined as hypercholesterolemia (total cholesterol greater than 240 milligrams per deciliter), hypertension (diastolic blood pressure greater than $90 \mathrm{~mm}$ of mercury), smoking, diabetes mellitus, or family history of premature CAD (heart attack or sudden cardiac death in a first-degree relative less than 60 years old). Given the LT's age with no defined risk factors, NFPA 1582 would not have recommended a symptomlimiting EST.

The ACC/AHA has also published exercise testing guidelines [Gibbons et al. 2002]. The ACC/AHA guideline states that the evidence to conduct stress tests in asymptomatic individuals is "less well established" (Class IIb) for the following groups:

- persons with multiple risk factors (defined similarly to those listed by the NFPA)

- asymptomatic men older than 45 years and women older than 55 years:

$\circ$ who are sedentary and plan to start vigorous exercise

o who are involved in occupations in which impairment might jeopardize public safety (e.g., fire fighters)

- who are at high risk for coronary artery disease due to other diseases (e.g., peripheral vascular disease and chronic renal failure)

Given the LT's public safety position, the ACC/ AHA criteria suggest an EST may have been appropriate for the LT.

The U.S. Department of Transportation provides guidance for those seeking medical certification for a commercial driver's license. An expert medical panel recommended exercise tolerance tests (stress tests) for asymptomatic "high risk" drivers [Blumenthal et al. 2007]. The panel defines high risk drivers as those with any of the following: 


\section{Lieutenant Suffers Sudden Cardiac Death During the "Pack Test"}

\section{- Arizona}

\section{Discussion (cont.)}

- diabetes mellitus

- peripheral vascular disease

- age 45 and above with multiple risk factors for CHD

- Framingham risk score predicting a 20\% CHD event risk over the next 10 years

Given the LT's Framingham risk score of $11 \%$, the U.S. Department of Transportation would not have recommended an EST for a commercial truck driver with a similar profile [NHLBI 2013].

The U.S. Preventive Services Task Force (USPSTF) does not recommend stress tests for asymptomatic individuals at low risk for CHD events. For individuals at increased risk for CHD events, the USPSTF found "insufficient evidence to recommend for or against routine screening with EKG, exercise tolerance test, or electron beam computerized tomography scanning...." Rather, they recommend the diagnosis and treatment of modifiable risk factors (hypertension, high cholesterol, smoking, and diabetes) [USPSTF 2004]. The USPSTF does note that "For people in certain occupations, such as pilots, and heavy equipment operators (for whom sudden incapacitation or sudden death may endanger the safety of others), consideration other than the health benefit to the individual patient may influence the decision to screen for coronary heart disease."

Had an EST been performed, perhaps the LT's CHD could have been identified, leading to further evaluation and treatment.

\section{Recommendations}

It is unclear if any of the following recommendations would have prevented the LT's death. Nonetheless, NIOSH investigators offer the following recommendations to reduce the risk of heart attacks and sudden cardiac arrest among fire fighters at this and other FDs.

Recommendation \#1: Provide preplacement and annual medical evaluations to all fire fighters in accordance with NFPA 1582, Standard on Comprehensive Occupational Medical Program for Fire Departments, to identify fire fighters at increased risk for CHD.

Guidance regarding the content and frequency of these medical evaluations can be found in NFPA 1582 and in the International Association of Fire Fighters (IAFF)/International

Association of Fire Chiefs (IAFC) Fire Service Joint Labor Management Wellness/Fitness Initiative [IAFF, IAFC 2008; NFPA 2013b]. These evaluations are performed to determine fire fighters' medical ability to perform duties without presenting a significant risk to the safety and health of themselves or others. Following this recommendation will require significant resources and may be particularly difficult for smaller fire departments to implement. The FD is not legally required to follow the NFPA standard or the IAFF/IAFC guideline.

To overcome the financial obstacle of medical evaluations, the FD could urge current members to get annual medical clearances from their private physicians. Another option is having the annual medical evaluations completed by paramedics and emergency medical technicians from the local ambulance service (vital signs, height, weight, visual acuity, and EKG). 


\section{Lieutenant Suffers Sudden Cardiac Death During the "Pack Test” - Arizona}

\section{Recommendations (cont.)}

This information could then be provided to a community physician (perhaps volunteering his or her time), who could review the data and provide medical clearance (or further evaluation, if needed). The more extensive portions of the medical evaluations (e.g., EST) could be performed by a private physician at the fire fighter's expense (personal or through insurance), provided by a physician volunteer, or paid for by the FD, city, or state. Sharing the financial responsibility for these evaluations between fire fighters, the FD, the city, the state, and physician volunteers may reduce the negative financial impact on recruiting and retaining needed fire fighters.

\section{Recommendation \#2: Perform exercise stress} tests on fire fighters at increased risk for CHD.

NFPA 1582, the IAFF/IAFC Fire Service Joint Labor Management Wellness/Fitness Initiative, and the $\mathrm{ACC} / \mathrm{AHA}$ recommend an exercise stress test for male fire fighters older than 45 with one or more CAD risk factors [IAFF, IAFC 2008; Gibbons et al. 2002; NFPA 2013b]. The LT was over the age of 45 and had borderline high blood cholesterol. A symptom-limiting EST may have identified his underlying CHD, possibly leading to further evaluation and treatment.

\section{Recommendation \#3: Check Pack Test} participants' vital signs before testing.

NFES 1109, Work Capacity Test Administrator's Guide, requires that an emergency medical technician (or someone with equivalent qualifications) observe candidates during and after the test, and be available to provide emergency medical assistance, if needed [Whitlock and Sharkey 2003]. The emergency medical technician should take participant vital signs (pulse, blood pressure, and respirations) before and after the WCTs to ensure that the participant does not have a precluding condition prior to the test, and that the participant's vital signs return to normal levels after the test. After this incident, the FD began requiring vital sign checks for all members performing strenuous physical exertion activities.

\section{Recommendation \#6: Require the completion of a HSQ prior to participating in the Pack Test.}

The WCT Administrator's Guide states that the candidate must complete an HSQ (or medical history) designated by the hiring agency before training for the WCT or the duties of the job [Whitlock and Sharkey 2003]. Depending on the results of the HSQ and the age of the candidate, the agency may require a medical examination. Once individuals have received medical clearance, they may begin training for the WCT. The test administrator reviews the forms and determines whether to allow participants to take the test. If the test administrator is concerned that an applicant is not capable of completing the test, the administrator may require a medical clearance from the applicant's primary care physician. In this instance, the State did not require that WCT candidates complete a HSQ prior to the Walk Test, the more arduous Field Test, or the most arduous Pack Test [Sharkey and Gaskill 2009]. Nonetheless, NIOSH investigators recommend the FD follow National Wildland Coordinating Group (NWCG) guidance. 


\section{Lieutenant Suffers Sudden Cardiac Death During the "Pack Test" \\ - Arizona}

\section{References}

AHA (American Heart Association) [2013].

Symptoms and diagnosis of pericarditis. Dallas, TX: American Heart Association. [http:// www.heart.org/HEARTORG/Conditions/More/ Symptoms-and-Diagnosis-of-Pericarditis UCM_444932_Article.jsp]. Date accessed: July 2014

AHA (American Heart Association) [2014]. Understand your risk of heart attack. Dallas, TX: American Heart Association. [http://www.heart. org/HEARTORG/Conditions/HeartAttack/UnderstandYourRiskofHeartAttack/Understand-YourRisk-of-Heart-Attack_UCM_002040_Article.jsp]. Date accessed: July 2014.

Amir O, Smith R, Nishikawa A, Gregoric ID, Smart FW [2005]. Left ventricular free wall rupture in acute myocardial infarction. Tex Heart Inst J 32(3):424-426.

Antman EM, Grudzien C, Sacks DB [1995]. Evaluation of a rapid bedside assay for detection of serum cardiac troponin T. JAMA 273(16):12791282.

Blumenthal RS, Epstein AE, Kerber RE [2007]. Expert panel recommendations. Cardiovascular disease and commercial motor vehicle driver safety. [http://www.mrb.fmcsa.dot.gov/documents/CVD_Commentary.pdf]. Date accessed: July 2014.

Braunwald E [2008]. Pericardial disease. In: Fauci AS, Braunwald E, Kasper DL, Hauser SL, Longo DL, Jameson JL, Loscalzo J, eds. Harrison's principles of internal medicine. 17th ed. New York: McGraw-Hill, pp. 1488-1495.
CDC (Centers for Disease Control and Prevention) [2014]. Assessing your weight. [http://www. cdc.gov/healthyweight/assessing/index.html]. Date accessed: July 2014.

Ellis AK [1991]. Serum protein measurements and the diagnosis of acute myocardial infarction. Circ 83(3):1107-1109.

Figueras J, Cortadellas J, Calvo F, Soler-Soler J [1998]. Relevance of delayed hospital admission on development of cardiac rupture during acute myocardial infarction: study in 225 patients with free wall, septal or papillary muscle rupture. J Am Coll Cardiol 32(1):135-139.

Figueras J, Cortadellas J, Soler-Soler J [2000]. Left ventricular free wall rupture: clinical presentation and management. Heart 83(5):499-504.

Gibbons RJ, Balady GJ, Bricker JT, Chaitman BR, Fletcher GF, Froelicher VF, Mark DB, McCallister BD, Mooss AN, O'Reilly MG, Winters WL Jr., Antman EM, Alpert JS, Faxon DP, Fuster V, Gregoratos G, Hiratzka LF, Jacobs AK, Russell RO, Smith SC Jr [2002]. ACC/AHA 2002 guideline update for exercise testing: a report of the American College of Cardiology/ American Heart Association Task Force on Practice Guidelines. Circulation 106(14):1883-1892.

IAFF, IAFC [2008]. The fire service joint labor management wellness/fitness initiative. 3rd ed. Washington, DC: International Association of Fire Fighters, International Association of Fire Chiefs. 


\section{Lieutenant Suffers Sudden Cardiac Death During the "Pack Test" - Arizona}

\section{References (cont.)}

Libby P [2008]. The pathogenesis, prevention, and treatment of atherosclerosis. In: Fauci AS, Braunwald E, Kasper DL, Hauser SL, Longo DL, Jameson JL, Loscalzo J, eds. Harrison's principles of internal medicine. 17th ed. New York: McGraw-Hill, pp. 1501-1509.

Libby P [2013]. Mechanisms of acute coronary syndromes and their implications for therapy. $\mathrm{N}$ Engl J Med 368(21):2004-2013.

Mair J, Diensti F, Puschendorf B [1992]. Cardiac troponin $\mathrm{T}$ in the diagnosis of myocardial injury. Crit Rev Clin Lab Sci 29(1):31-57.

Meyerburg RJ, Castellanos A [2008]. Cardiovascular collapse, cardiac arrest, and sudden cardiac death. In: Fauci AS, Braunwald E, Kasper DL, Hauser SL, Longo DL, Jameson JL, Loscalzo J, eds. Harrison's principles of internal medicine.

17th ed. New York: McGraw-Hill, pp. 1707-1713.

NFPA [2013a]. Standard on fire department occupational safety and health program. Quincy, MA: National Fire Protection Association. NFPA 1500.

NFPA [2013b]. Standard on comprehensive occupational medical program for fire departments. Quincy, MA: National Fire Protection Association. NFPA 1582.

NHLBI [2012]. Who is at risk for coronary artery disease? National Heart, Lung, and Blood Institute. [http://www.nhlbi.nih.gov/health/health-topics/topics/cad/atrisk.html]. Date accessed: July 2014.
NHLBI [2013]. Risk assessment tool for estimating your 10-year risk of having a heart attack. National Heart, Lung, and Blood Institute. [http:// cvdrisk.nhlbi.nih.gov/calculator.asp]. Date accessed: July 2014.

NIH (National Institutes of Health) [2014]. Troponin test. [http://www.nlm.nih.gov/medlineplus/ ency/article/007452.htm]. Date accessed: July 2014.

Neumar RW, Otto CW, Link MS, Kronick SL, Shuster M, Callaway CW, Kudenchuk PJ, Ornato JP, McNally B, Silvers SM, Passman RS, White RD, Hess EP, Tang W, Davis D, Sinz E, Morrison LJ [2010]. Part 8: Adult advanced cardiovascular life support. 2010 American Heart Association Guidelines for cardiopulmonary resuscitation and emergency cardiovascular care. Dallas, TX: American Heart Association.

OSHA [2011]. Respiratory protection. Occupational Safety and Health Administration. [https:// www.osha.gov/pls/oshaweb/owadisp.show document?p_table=STANDARDS\&p_id=12716]. Date accessed: July 2014.

Raposo L, Andrade JM, Ferreira J, Aguiar C, Couto R, Abecasis M, Canada M, Jalles-Tavares N, da Silva JA [2006]. Subacute left ventricle free wall rupture after acute myocardial infarction: awareness of the clinical signs and early use of echocardiography may be life-saving. Cardiovascular Ultrasound 4(1):46-54.

Sharkey BJ, Gaskill SE [2009]. Fitness and work capacity. NWCG. [http://www.nwcg.gov/pms/ pubs/pms304-2.pdf]. Date accessed July 2014. 


\section{Lieutenant Suffers Sudden Cardiac Death During the "Pack Test" \\ - Arizona}

\section{References (cont.)}

Thaulow E, Erikssen J, Sandvik L, Erikssen G, Jorgensen L, Cohn PF [1993]. Initial clinical presentation of cardiac disease in asymptomatic men with silent myocardial ischemia and angiographically documented coronary artery disease (The Oslo Ischemia Study). Am J Cardiol 72(9):629-633.

USPSTF [2004]. U.S. Prevention Services Task Force. Screening for coronary heart disease: Recommendation Statement. Ann Intern Med 140(7):569-572.

Whitlock C, Sharkey B [2003]. Work Capacity Test Administrator's Guide. NWCG. [http://www. nwcg.gov/pms/pubs/PMS307.pdf]. Date accessed July 2014.

\section{Investigator Information}

This incident was investigated by the NIOSH Fire Fighter Fatality Investigation and Prevention Program, Cardiovascular Disease Component in Cincinnati, Ohio. Mr. Tommy Baldwin (MS) led the investigation and co-authored the report. Mr. Baldwin is a Safety and Occupational Health Specialist, a National Association of Fire Investigators (NAFI) Certified Fire and Explosion Investigator, an International Fire Service Accreditation Congress (IFSAC) Certified Fire Officer I, and a former Fire Chief and Emergency Medical Technician. Dr. Thomas Hales (MD, MPH) provided medical consultation and co-authored the report. Dr. Hales is a member of the NFPA Technical Committee on Occupational Safety and Heath, and Vice-Chair of the Public Safety Medicine Section of the American College of Occupational and Environmental Medicine (ACOEM). 


\section{Lieutenant Suffers Sudden Cardiac Death During the "Pack Test" \\ - Arizona}

\section{Appendix A}

\section{Autopsy Findings}

- Transmural left ventricular tear in a focal area of necrotic tissue

- Cardiac tamponade due to hemopericardium (400 cc of blood in pericardial sac)

- Coronary artery atherosclerosis

- $90 \%$ narrowing of the left anterior descending coronary artery with small adherent thrombus (blood clot)

- $60 \%$ focal narrowing of both the circumflex coronary artery and the right coronary artery

- Hypertensive heart disease

$\circ$ Mild left ventricular hypertrophy (1.9 centimeter $[\mathrm{cm}])$

- Normal at autopsy is 0.76-0.88 cm [Colucci and Braunwald 1997] Borderline cardiomegaly (heart weighed 420 grams [g]; predicted normal weight is $349 \mathrm{~g}$ [ranges between $265 \mathrm{~g}$ and $461 \mathrm{~g}$ as a function of sex, age, and body weight]) [Silver and Silver 2001]

- Normal cardiac valves

- No evidence of a pulmonary embolus (blood clot in the lung arteries)

- Negative drug and alcohol tests

\section{References}

Colucci WS, Braunwald E [1997]. Pathophysiology of heart failure. In: Braunwald, ed. Heart disease. 5th ed. Philadelphia, PA: W.B. Saunders Company, p. 401.

Silver MM, Silver MD [2001]. Examination of the heart and of cardiovascular specimens in surgical pathology. In: Silver MD, Gotlieb AI, Schoen FJ, eds. Cardiovascular pathology. 3rd ed. Philadelphia, PA: Churchill Livingstone, pp. 8-9. 


\section{Lieutenant Suffers Sudden Cardiac Death During the "Pack Test" - Arizona}

\section{Appendix B}

\section{Physical Agility Test - Performed Annually}

1. Hose Placement: The station is set up at the back of the engine that the candidate is stepping out of. If the rear tailboard is too narrow, utilize a folding table. The six $2 \frac{1}{2}$-inch hose rolls will be placed 6-feet from the table and stacked in 3 stacks of two each. The candidate picks up one roll at a time and places the roll onto the tailboard until 3 stacks of two are on the tailboard. Then, pausing by standing upright before resuming, the candidate replaces the hose to the original position.

2. High Rise Pack/Stair Climb: Carry the 100-feet, 13/4-inch high rise pack placed at the bottom of the stairs. The candidate places the pack on his/her shoulder and walks up the steps without skipping a step. Both feet are placed on the landing or ground prior to turning around. The candidate will hold onto the rail or wall with one hand for stability during this station. The candidate will go up twice and down once before placing the pack at the top of the stairs.

3. Hose Lift: One $2 \frac{1}{2}$-inch taped hose roll is lying flat on the ground with a 50 -foot rope attached and draped over the rail. The candidate will pull the hose up and over the rail, placing it on the landing.

4. Ladder Climb: The 24-foot ladder is placed between Bay 1 and Bay 2 and extended to be able to reach the ceiling by the "bell." The candidate will climb the ladder one rung at a time and climb until he/she strikes the "bell" on the metal portion and then climbs down the ladder to the ground. The ladder will be tied off to the bay and roof to prevent slippage and spotters will be utilized on each side of the ladder.

5. Ventilation Exercise: The weighted sled will be placed at the first screw marks on the Kaiser sled and will be struck as many times as necessary to move the sled until one end passes the opposite edge of the sled. Prior to every 5 th person attempting the station, the sled will be wiped down with a light coat of oil.

6. Ceiling Pull Exercise: The candidate, keeping one hand on the 8-foot pike pole at all times and never sliding or losing control of the pole, will hook the metal edge of the interior of the building and give a tug to set the pole. Unhooking and lowering the pole to the ground will constitute one repetition. A total of 15 repetitions is required.

7. Water Tender/Engine Connection: Placing the water tender 45 -feet from the engine and at an angle to leave room for the candidate to walk between them, the candidate will pull a section of $2 \frac{1}{2}$-inch hose from the center bed of the water tender and make the connection at the engine for incoming water on the captain's side. The candidate will then make the connection at the water tender on the engineer side discharge. All connections will be hand tight. 


\section{Lieutenant Suffers Sudden Cardiac Death During the "Pack Test" \\ - Arizona}

\section{Appendix B (cont.)}

8. Hose Pull: The two 13/4-inch hoselines are connected and placed in an "S" pattern by the engine. The candidate will pick up the hose and extend it until just past the edge of the station building or until extended without jerking. The candidate can run/jog on this station.

9. Rescue Drag: The 140-pound mannequin will be placed with the head toward the bay lying flat on the ground. The candidate will pick up the mannequin in whatever manner they choose and drag or carry the object 45 -feet around the barrel without using the barrel as a fulcrum and return to the station starting line. Time is complete when the mannequin's feet cross the line.

The test is a timed test which must be completed within 5 minutes. The following rules apply:

1. No running at any time, except during the hose pull. (10 second penalty)

2. Face inward while stepping off the apparatus and utilize all safety devices, such as hand rails, steps, etc. (5 second penalty)

3. Do not drop any equipment on the ground including but not limited to nozzles, couplings, hose packs, pike pole, etc. (5 second penalty)

4. Sliding the pike pole through hands or not maintaining control of the pike pole. (5 second penalty)

5. Not hooking the pike pole over the rail or touching the ground. (No time penalty but repetition doesn't count)

6. Not hand over hand on the hose raise. (5 second penalty)

7. Skipping steps on the stair climb. (5 second penalty)

8. Not "sinking your heels" on the ladder climb. (3 second penalty)

9. Coupling not hand tight on the water tender connection. (10 second penalty)

10. Failing to pause/stand tall after placing hoses on tailboard/table. ( 5 second penalty)

11. Lift with your legs, not your back. (No penalty, but enforced)

12. One hand on the hand rail or wall during the stair climb. (5 second penalty)

One warning may be given per infraction to remind the candidate about the rules. 